\title{
Depression in the Context of Medical Disorders: New Pharmacological Pathways Revisited
}

\author{
Undine E. Lang Marc Walter
}

University of Basel, Department of Psychiatry and Psychotherapy, University Psychiatric Hospitals, Basel, Switzerland

\section{Key Words}

Depression • Cancer $・$ Inflammation $•$ Diabetes $\bullet$ Dementia $\bullet$ Cardiovascular Disease

\begin{abstract}
The depressive state has been characterised as one of elevated inflammation, changed cardiovascular parameters and a deranged metabolic situation all of which holds promise for a better understanding and handling of treatment-resistance in affective disorders as well as for future developments in treatment algorithms. In this context several biomarkers are differentially regulated by antidepressant treatment and connected to metabolic, inflammatory, cardiovascular and apoptotic components of the pathophysiology, i.e. adiponectin, apolipoprotein-B, B-type natriuretic peptide, cortisol, CRP, cysteine, homocysteine, fibrinogen, adiponectin, BMI, glycated hemoglobin A1c, leptin, interferon-gamma, high-density lipoprotein, interleukin interleukin-1alpha, -1beta, $-2,-4,-5,-6,-8,-10,-12,-13,-17$, insulin-like growth factor-1, low-density lipoprotein, myeloperoxidase, osteoprotegerin, tumour necrosis factor alpha, troponins, triglycerides etc. In this context antidepressants exert different modulatory effects on the outcome, incidence and mortality concerning several severe disorders, i.e. cancer, diabetes, stroke, inflammation, stroke and cardiovascular risk. Vice versa different drugs used in the treatment of these disorders have a favourable effect in depressive states, e.g. statins, aspirine, NSAIDs, pioglitazone, celecoxib, peroxisome proliferator-activated receptorgamma agonists and minocycline. In this review, actions of different antidepressant treatment strategies on cancer, stroke, diabetes and cardiovascular disorders are shown and the influence on the outcome of the disorders is differentially discussed. In conclusion a hypothetic model for the implication of actual findings in everyday clinical practice is proposed. In this context personalized treatment could be used to tailor treatment to specific individuals according to their clinical endophenotypes. Moreover a potential target for the development of novel intervention strategies might be used.
\end{abstract}

\section{Introduction}

The results from studies from controlled trials concerning elderly patients with medical comorbidities (cardiovascular disorders, diabetes, dementia, cancer) are insufficient [1]. 
Lang/Walter: Depression and Comorbidity

Depression increases the risk of severe physical disorders such as cancer, diabetes, stroke, inflammation and acute coronary syndrome through multiple molecular mechanisms [2] (see Fig. 1). Moreover, depression has an adverse impact on the course of these disorders with more funcional impairments, more complications, higher mortality and poorer quality of life and compliance. However, depression is often connected with stress and a live style, which implies smoking, low physical exercise, sleep disturbances, less social activities and unhealthy nutrition. These habits again can lead to a significant proportion of inflammatory, atherogenic and metabolic risk factors that might lead to the significant increase of the prevalence and severity of cardiovascular, cancer and metabolic diseases (see Fig. 1). To appropriately manage depression in these patients and increase life quality, outcome of the physical disorder, life expectancy and adherence antidepressant treatment should be provided and has proven to be successful. However, the differential influence of antidepressant strategies on the specific physical disorder is not easy to examine as different antidepressant strategies result (at least in retrospective population surveys) from different clinical subtypes of patients and therefore the influence of depression per se and the antidepressant on the physical disorder is complex and often not separable. Moreover, patients suffering from a medical disorder and are additionally depressed might not be comparable wth patients suffering from a medical disorder who are not depressed as depression per se might separate patients who are stronger affected also from the somatic disorder.

Several biomarkers relevant for different facets of depressive disorders are differentially regulated by antidepressant treatment and connected again to metabolic, inflammatory, cardiovascular and apoptotic components of the pathophysiology, i.e. adiponectin, apolipoprotein-B, B-type natriuretic peptide, cortisol, C-reactive protein, cysteine, homocysteine, fibrinogen, growth-differentiation factor-15, glycated hemoglobin A1c, leptin, high-density lipoprotein, interleukin-6, insulin-like growth factor-1, low-density lipoprotein, myeloperoxidase, osteoprotegerin, tumor necrosis factor- $\alpha$, troponins, triglycerides [3] (see Fig. 1).

The objective of the present review is to present different hypothesized influences of antidepressants on clinical correlates of different physical disorders and hypothesized pathophysiological mechanisms of medical treatments on depression. In particular the influence of antidepressants on cancer, stroke, diabetes and acute coronary syndrome are shown and the treatment of these physical disorders on the course of depression. This review will ideally enhance our current treatment strategies of associated serious medical conditions and possibly will allow clinicians to develop more advanced and personalized treatment options for these patients in routine practice or at least explain special clinical cases occurring typically in the everyday clinical routine.

\section{In patients with cancer think about tricyclic antidepressants}

Depression is common after a cancer diagnosis and is associated with an increased mortality, however, depression is often occurring before the cancer diagnosis and increases cancer mortality [4] (see Fig. 1). Two decades ago, it was hypothesized that antidepressants could alter the course of neoplastic diseases. However, contradictory findings indicated that antidepressants could either have carcinogenic properties or improve the disease outcome. An important aspect of future experiments will be to continue to investigate the signaling networks perturbed by these drugs in cancer cells. For example, in our own experiments, we found that the PI3K mTor pathway might be linked to depressive behavior in mice $5,6]$ and man $[7,8]$. Therefore antidepressants might evolve their actions far beyond the monoamine hypothesis influencing at ways which are involved in cancer development and progression. Intriguingly, controversial results were reported on the action of antidepressant drugs on immune function. Further hypotheses proposed that antidepressants could 


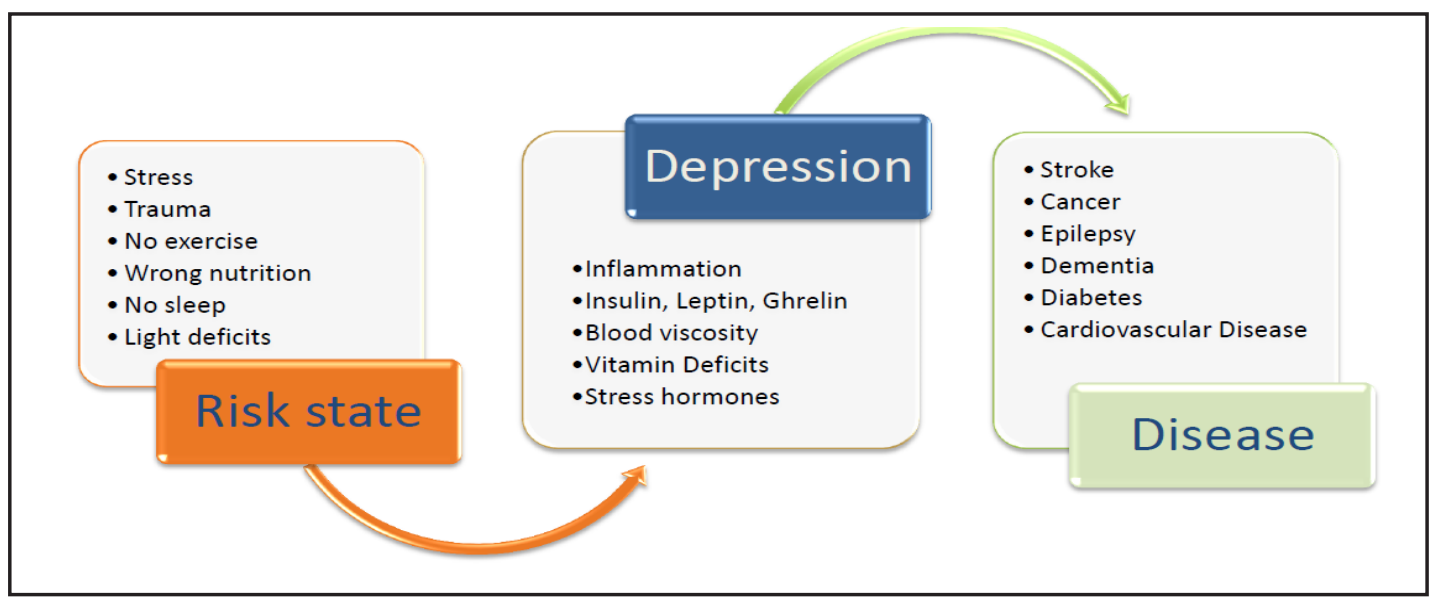

Fig. 1. Depression often occurs with comorbid medical conditions. Common risk factors might leading to both; depression and medical disorders.

indirectly affect cancer prognosis through the modulation of antitumor activity. Here we review the literature in order to elucidate the influence of antidepressants on cancer and immunity. The immune system, i.e. innate immune activation, inflammation and suppression of the immune system have been shown to play a role in the pathogenesis of depression and neoplastic growth. Cancer patients experience a threefold higher rate of depression within the first five years of diagnosis and vice versa depression is associated with increased cancer risk and shortened survival. In this contex cancer patients often need antidepressant treatment and research is needed to determine whether differential antidepressant treatment improves cancer survival. It is essentiell to develop antidepressant strategies that target neurobiological pathways mediating both, oncogenesis and depression and the underlying molecular and cellular mechanisms that influence pathophysiological cascades of both disorders. Several studies suggested that antidepressant use might increase or decrease the risk of cancer occurrence, depending on specific cancer types. Whereas bipolar disorder was not associated in a nationwide Swedish study with increased cancer incidence and with lithium treatment, there was an increased risk of respiratory, gastrointestinal, and endocrine cancer in patients with bipolar disorder without lithium treatment [9].

Colon cancer is one of the most common tumors worldwide, with increasing incidence in developing countries. Patients treated with fluoxetine have a reduced incidence of colon cancer, although there still remains great controversy about the nature of this effect [10]. Experimental evidence indicates that serotonin is associated with both proliferative and procarcinogenic effects on colorectal tumors. However, in colorectal cancer, selective serotonin reuptake inhibitors, tricyclic antidepressants, serotonin-norepinephrine reuptake inhibitors, and serotonin antagonist and reuptake inhibitors were not associated with increased incidence of the disease in humans [11]. Monoamine oxidase inhibitors were associated with an increased incidence of colorectal cancer and higher cumulative dose of mirtazapine was associated with a decreased incidence of colorectal cancer [11]. Lithium accumulates in the colon and inhibits the enzyme GSK-3beta that possesses anti-carcinogenic effects, however, lithium use was not associated with an overall increased risk of colorectal adenocarcinoma [12].

The "repositioning" of an existing drug to treat a disorder other than the one for which it was originally approved is an example of how extremely large genetic and biological databases are changing the face of medicine [13]. In this context, three novel and still unknown compounds against colorectal cancer were computationally predicted amongst one is citalopram [13]. Citalopram as a potential therapeutic option for patients with colorectal cancer has been verified by in vitro assays of clonogenic survival, proliferation, and migration and in a subcutaneous mouse model [14]. 
Cancer stem cells are the cell population responsible for lung cancer chemoresistance and are a very good model for testing new targeted therapies. Clomipramine is able to potentiate the pro-apoptotic effects of DNA damaging induced agents in several cancer cell lines. Desmethylclomipramine inhibits lung cancer stem cell growth, decreases their stemness potential and increases the cytotoxic effect of conventional chemotherapeutic drugs [15]. Mirtazapine caused a substantial up-regulation of the Lin-7C/ $\beta$-catenin pathway in metastatic human small cell cancer cell lines and human melanoma-derived cell lines in vitro, and up-regulation did not contribute to cellular proliferation. Moreover, the antimetastatic effect of mirtazapine in these metastatic cell lines in vivo also was evident in multiple organs of immunodeficient mice with no marked side effects [16].

Furthermore, the antidepressant imipramine has been discussed recently to be potentially effective in combating small cell lung cancer, according to a study in labaratory mice from researchers at the Stanford University School of Medicine [17]. Indeed, basic research studies in mice are suggesting that cisplatin-resistant tumors are still sensitive to imipramine treatment [16]. An increased survival in patients with small cell lung carcinoma possibly linked to imipramine treatment might suggest this drug also in off label use in patients suffering from other tumors, including glioma, colorectal cancer and retinoblastoma, which has been suggested at least by epidemiological studies $[18,19$ (see Fig. 2).

Long-term use of tricyclic antidepressants has been associated in a nation-wide study with a reduced risk of glioma but not for serotonin reuptake inhibitors [20]. Hypericin targets multiple mechanisms in human glioblastoma tumor cell lines via unique manners [21]. It induces neuroglial tumor cell differentiation modulating the cytoarchitecture, neuroglial differentiation antigen expression and causes exit from cell proliferation cycles and has been discussed to constitute a novel anti-glioblastoma therapeutic paradigm [21]. Evidence shows that antidepressants decrease cancer incidence of glioblastoma and improve patients'

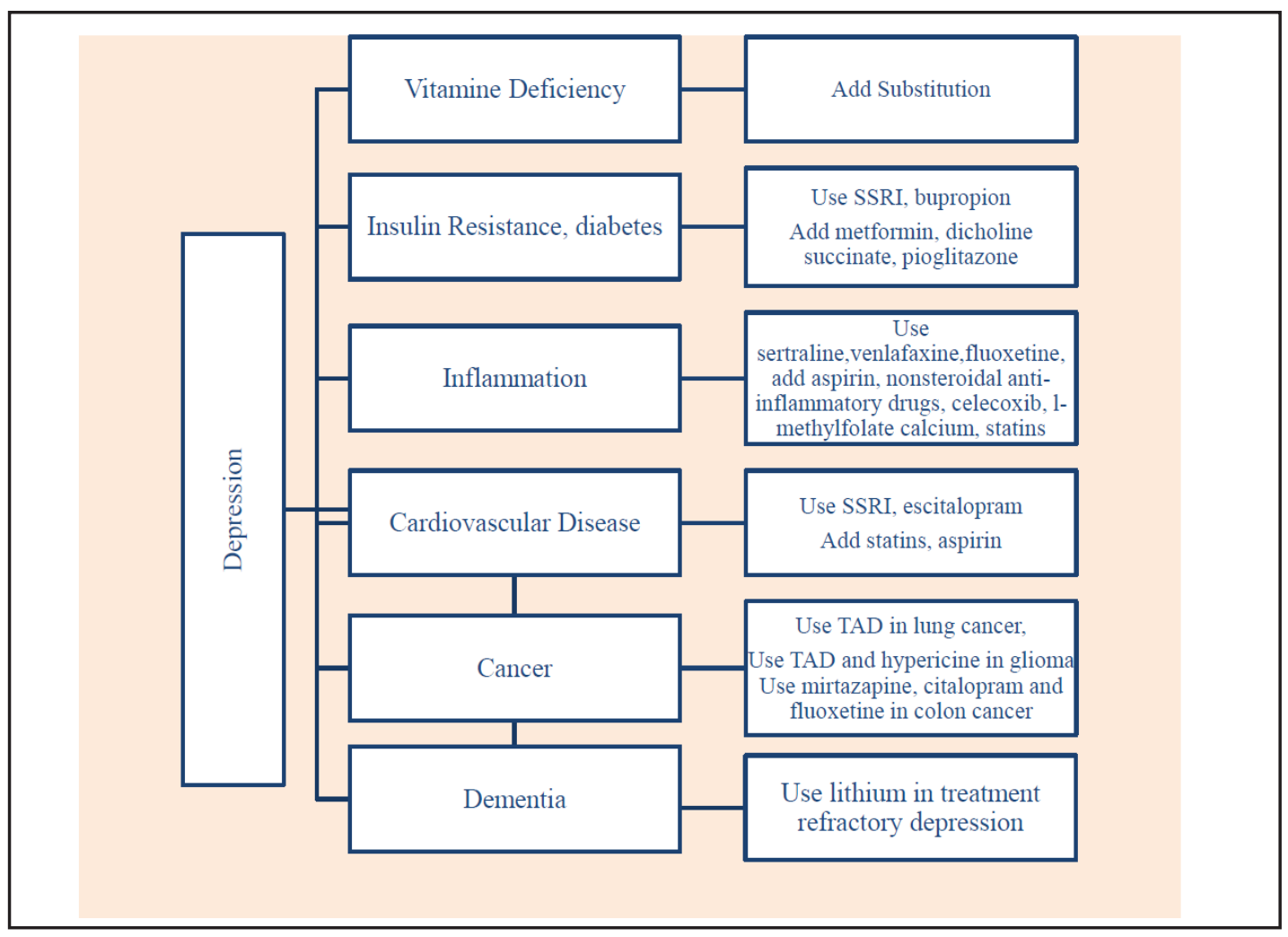

Fig. 2. Depressed individuals with different comorbid disorders should be treated differently. 
quality of life [22]. Selectively fluoxetine suppressed the growth of glioblastomas in brains of mice, an effect similar to that produced by temozolomide in preclinical studies, which has been hypothesized to provide a new approach for managing this disease [22].

Paroxetine was associated with a 620 percent increase in the rate of breast cancer in women who had taken it over a four-year period and as the highest inhibitory constant for the P-450-2D6 isoenzyme of all antidepressants which implies an increased probability of oncogenesis [23]. However there was no evidence for an association between overall antidepressant prescription and the risk of breast cancer risk [24]. Although controversy exists about whether certain antidepressants reduce tamoxifen's effectiveness on lowering breast cancer recurrence, no increased risk of subsequent breast cancer in women who concurrently used tamoxifen and antidepressants, including paroxetine was observed recently in a large study and no evidence was found that either depression or antidepressant use influences breast cancer risk [25].

The use of antidepressants and the occurrence of oral cancer have been studied and selective serotonin reuptake inhibitors and tricyclic antidepressants were associated with a reduced risk of oral cancer [26]. The association between antidepressant use and a decreasing oral cancer risk were demonstrated by both prospective and nested case-control studies [26].

Lithium induces proliferation in the epithelium of renal collecting ducts, however in a nationwide case-control study, use of lithium was not associated with an increased risk of upper urinary tract cancer [17].

Fluoxetine appears to exhibit an apoptotic effect against Hep3B cells through the loss of mitochondrial membrane potential, formation of reactive oxygen species and modulation of mitogen-activated protein kinases activities. In this context, fluoxetine might inhibit cell growth and have an antitumor effect at least in human hepatocellular carcinoma cell lines [27].

Little evidence has found that the use of tricyclic antidepressants increases the risk of non-Hodgkin lymphoma overall or for specific common subtypes of non-Hodgkin lymphoma [28]. Amitriptyline showed potent activity in inducing multiple myeloma cell apoptosis in vitro, decreased tumor growth, decreased antiapoptotic Bcl-2 and Mcl-1 in tumor tissues and extended the survival period of multiple myeloma tumor-bearing mice [29].

Nortriptyline induces both intrinsic and extrinsic apoptosis in human and mouse bladder cancer cells and has been discussed a clinically useful chemotherapeutic agent for bladder cancer in humans [30] (see Fig. 2).

In conclusion more controlled studies are needed to show effects of antidepressants on tumor activity and outcome. Concerning the depressive symptomatology there are to our knowledge only two controlled studies comparing different medications in cancer patients i.e. paroxetine versus desipramine and mirtazapine versus imipramine $[31,32]$. In this context there are at the moment no concluding remarks possible concerning the differential influences of antidepressant treatments in cancer patients [31, 32].

\section{In patients with cardiovascular disorders use serotonin reuptake inhibitors}

A close, bidirectional relationship exists between depression and cardiovascular disease. Indeed, depression is associated with an increased risk of coronary artery disease, myocardial infarction, congestive heart failure, and isolated systolic hypertension leading to increased mortality and morbidity in patients [33]. However, the rate of rehospitalizations due to cardiovascular events seems to decrease after antidepressant treatment [33] (see Fig. 1).

The comorbidity between depression and cardiovascular disorder includes changes of the central and autonomic nervous, hematologic, neuroendocrine, immune and vascular system. An imbalance between the sympathetic and parasympathetic systems, a loss 
of heart rate variability, sympathoadrenal activation, blood viscosity, increase of proinflammatory cytokines with concomitant hypothalamic-pituitary-adrenal axis activation, hypercortisolemia, immune system dysregulation, platelet activation and hypercoagulability have been demonstrated in most individuals diagnosed with major depressive disorder [2] (see Fig. 1). Collaborative depression care delivered before cardiovascular disease onset halves the excess risk of cardiovascular disease events among older, depressed patients [34]. Additionally, at least in chronically depressed individuals, an $80 \%$ or higher antidepressant adherence lead to a $26 \%$ lower risk of hospitalizations in terms of coronary artery disease when compared to patients with a less than $80 \%$ adherence [35].

In this context, the prevailing view is, that improvement in depression is necessary to improve cardiovascular outcome. For example, sertraline resulted in greater reductions in depressive symptoms compared to placebo in patients with coronary heart disease and this substance has been evidenced to improve cardiovascular biomarkers and may have a beneficial effect on clinical outcomes as well as on quality of life [36].

However, an improved cardiac status might result in reduced symptoms of depression and reduced symptoms of depression might lead to a better compliance concerning treatment of cardiosvascular symptoms. In this context, patients whose depression improve also exhibit improved cardiovascular outcomes and lower mortality and the beneficial influence of antidepressants on cardiovascular parameters per se is uncertain and not suggested in all studies. In this context, in a study, where antidepressant treatment generated modest symptom reductions, antidepressants did not improve symptoms more than placebo in 2 heart failure trials [37]. Moreover, in patients with heart failure depressive symptoms, not antidepressant therapy predicted event-free survival but depressive patients without antidepressants had a 4.1 times higher risk of death and hospitalization than non-depressed patients on antidepressant treatment [38].

In another study, implementing an antidepressant treatment strategy did not reduce the risk of cardiovascular morbidity and mortality compared to usual care but receiving antidepressant treatment increased survival [39]. It remains unclear whether this represents a direct antidepressant treatment effect or if this is due to associated factors that relate to both receiving depression treatment and mortality, such as patients' intrinsic motivation to care for their health [39]. Among post-coronary artery bypass graft surgery patients with mild to moderate depression in a parallel, double-blind, placebo-controlled trial simvastatin or atorvastatin demonstrated a significant effect for timextreatment interaction on depression severity and treatment with simvastatin showed a superior antidepressant effect when compared to atorvastatin [40]. The examination of data collected from 961 men participating in an Osteoporosis Study showed that documented exposure to statin and aspirin was associated with a reduced likelihood of mayor depression, i.e. among the 210 participants exposed to statins or aspirin, $2.9 \%$ in comparison to $5.4 \%$ developed de novo major depression 41] (see Fig. 2).

Overall, a decreased risk of developing depression has been reported among statin users [40]. Aside from their lipid-lowering effects, statins are considered immunomodulatory agents and have protective effects against oxidative stress and inflammation which are well known for their association with depression [40] (see Fig. 2).

However, in particular, a reduced risk of myocardial infarction with selective serotonin reuptake inhibitors, particularly fluoxetine was found; however the tricyclic drug lofepramine increased the risk of myocardial infarction in a prospective trial [42]. Antidepressant use and serotonin and norepinephrine reuptake inhibitors were associated with lower baroreflex sensitivity, which was not connected to depressive symptoms per se [43]. Beneficial effects of selective serotonin reuptake inhibitors, i.e. fluvoxamine were demonstrated on ischemiareperfusion injury, which is in line with the observation that serotonin is activated during ischemia-reperfusion and triggers contractile dysfunction and pathological apoptosis [44, 45]. Paroxetine was discussed a new pharmacological agents for heart failure therapy [46] (see Fig. 2). 
Amitriptyline, fluoxetine and tranylcypromine relax rat aorta in vitro [47] and duloxetine but not escitalopram significantly increase pulse wave velocity (the gold standard measure for arterial stiffness) in older depressed patients after 12 months of treatment [48].

Patients chronically medicated with serotonin reuptake inhibitors exhibit lower platelet serotonin content and reduced platelet aggregation induced by ADP, collagen and epinephrine which may also explain the increased bleeding risk associated with chronic serotonin reuptake inhibitor treatment as well as the reported beneficial effect of these substances in prevention of recurrent myocardial infarction [49] (see Fig. 2).

Adverse effects precipitated by the tricyclic drug desipramine include prolonged QT intervals, torsade de pointes tachycardia, heart failure, and sudden cardiac death [50]. QT prolongation has been primarily attributed to acute blockade of hERG/ $\mathrm{I}(\mathrm{Kr})$ currents, i.e. direct hERG channel block, acute reduction of hERG surface expression, chronic disruption of hERG trafficking, and induction of apoptosis 50]. Serotonin-norepinephrine reuptake inhibitors were approved without cardiovascular safety data despite the fact that they raise blood pressure [51].

New generation selective serotonin reuptake inhibitors cause a reduced cardiovascular morbidity and mortality, which may again be related to serotonin platelet abnormalities in depressed patients that are effectively treated [51]. Indeed, fluoxetine, paroxetine, sertraline and citalopram are not only considered to be free from the cardiotoxicity of their predecessors but also to function as safe and efficacious agents against depression, platelet activation, atherosclerosis and development and prognosis of coronary heart disease [49]. Also statins showed an antidepressant effect in a systematic review and meta-analysis [52].

In a register-based cohort study in Denmark the incidence of depression after stroke was $25 \%$ compared with $7.8 \%$ in the control population [53]. Depressed individuals, especially those with new onset, had increased all-cause mortality, for natural and unnatural causes of death [53]. On the contrary, a matched cohort study in 5.015 subjects showed that patients with a depressive episode had significantly higher rates of stroke $4.3 \% \mathrm{vs}$. $2.8 \% 9$ [54]. Patients with depression are at greater risk of developing a pathophysiological constitution that may in turn lead to stroke [54]. In addition, both depressive symptoms and taking antidepressant medications are associated with higher risk of stroke [54]. In a matched cohort study patients with a major depressive episode had significantly higher rates of stroke during the nine year follow up period. Greater severity of depression, but not greater use of antidepressants, preceded the occurrence of stroke [54].

In this context, retrospective studies where the use of antidepressants is associated with a higher risk of stroke are difficult to be interpreted. Example given, the use of tricyclic antidepressants, but not serotonin uptake inhibitors or other antidepressants was associated with an increased risk of stroke recurrence. However tricyclic antidepressants are normally used in clinical practice in more severe depressive states than serotonin reuptake inhibitors. Therefore the severity of depression rather than the antidepressant itself might count for stroke recurrence in these patients. This might be in line with the fact that recurrent stroke is particularly elevated when the tricyclic antidepressant treatment is abruptly cessated [55 . Furthermore, all-cause mortality but not the risk of stroke recurrence was higher in patients with stroke and controls treated with benzodiazepines, antidepressants and antipsychotics than in their untreated counterparts [56].

In patients with chronic heart failure and depression, 18 months of treatment with escitalopram compared with placebo did not significantly reduce all-cause mortality or hospitalization, and there was no significant improvement in depression. These findings do not support the use of escitalopram in patients with chronic systolic heart failure and depression [57]. In conclusion, a successful treatment of depressive symptoms per se might reduce the risk of recurrent stroke rather than the antidepressant use itself. In this context, treatment with antidepressants seems to also decrease the risk of developing dementia, i.e. veterans who developed dementia were treated with antidepressants for a significantly shorter duration than matched veterans who did not develop dementia [58]. 
In conclusion, in patients with cardiovascular disorders tricyclic antidepressants have been proved to show unfavorable side effects, increase the risk of myacardial infarction and lead to arrhythmia and cardiac arrest [59]. However, SSRI seem to have less serious side effects but citalopram and escitalopram may lead to changes of the QT-interval and torsades de pointes [60].

\section{In patients with diabetes use serotonin reuptake inhibitors}

Diabetes and insulin resistance are associated with altered brain imaging, depression, and increased rates of age-related cognitive impairment. However, metabolic dysregulation influences brain function and disturbances in peripheral glucose regulation might be associated with cognitive impairment and depressed mood [2, 61] (see Fig. 1). Depression is highly associated with obesity, metabolic syndrome and type-2 diabetes [2, 62-64] and it has even been discussed to classify depression as metabolic syndrome type II $[2,65]$. The presence of depressive symptoms is documented in 12.8-29\% of males and $23.8-30.5 \%$ of females with newly diagnosed diabetes. Diabetes has in turn been shown to affect the incidence of depression $[2,65]$ and depressive symptoms are predictive of poor glycemic control in type 2 diabetes mellitus patients $[2,66]$ (see Fig. 1). The occurrence of depression was found to precede the onset of diabetes and was hypothesized to be associated with inherited inter-related insufficiency of the peripheral and central insulin receptors [67].

A number of epidemiological studies have established a link between insulin resistance and the prevalence of depression. In a retrospective study in 923.024 patients an association between hypoglycemic events and depression has been observed in patients with diabetes mellitus, i.e. patients reporting hypoglycemic events had 78\% higher odds of experiencing depression than patients without hypoglycemic events [68].

Selective serotonin reuptake inhibitors are recommended if possible to treat a depression among patients with diabetes [69] (see Fig. 2). Antidepressant treatment in patients with diabetes and depressive symptoms showed a reduction in depressive symptoms after treatment with an antidepressant in the acute as well as during maintenance phase [69]. Indeed, the depression improvement had a favourable effect on glycaemic control that was weight independent [69].

A brain-specific knockout of the insulin receptor leads to increased levels of monoamine oxidase $A$ and $B$ leading to increased dopamine turnover in these areas as a direct consequence of loss of insulin signalling [70]. Thus, insulin resistance in brain induces mitochondrial and dopaminergic dysfunction leading to anxiety and depressive-like behaviors, demonstrating a potential molecular link between central insulin resistance and behavioral disorders [70]. Indeed, selective serotonin reuptake inhibitors, i.e. paroxetine, fluoxetine or sertraline inhibit dose-dependent insulin-induced Tyr phosphorylation of insulin receptor substrate 2 protein and the activation of its downstream targets Akt and the ribosomal protein S6 kinase-1, which correlated with a rapid dephosphorylation and activation of the insulin receptor substrate kinase GSK3-beta [71]. Therefore an inhibition of the insulin secretion by serotonin reuptake inhibitors has been suggested and that these drugs might accelerate the transition from an insulin-resistant state to overt diabetes [71].

Diabetes related vascular pathology arises from mitochondrial reactive oxygen species generation, which contributes to endothelial dysfunction and diabetic vasculopathy. In a novel cell-based screening approach of known pharmacological compounds paroxetine has been identified a new property as a potent inhibitor of mitochondrial reactive oxygen species generation [72].

Improvement in depression scores was associated with improvement in biomarkers of insulin resistance, i.e. oral glucose tolerance test and fasting plasma glucose [73] (see Fig. 1).

Selective agonists of the nuclear transcription factor peroxisome proliferator-activated receptor-gamma are used for the treatment of type- 2 diabetes. In a recent metaanalyses 
resulting from 4 open-label trials and 4 randomized controlled trials in 448 patients peroxisome proliferator-activated receptor-gamma agonists have antidepressant effects in the 4 open-label studies and in 3 out of 4 RCT [73]. Pioglitazone, either alone or as addon therapy to conventional treatments, could induce remission of depression, suggesting that drugs with peroxisome proliferator-activated receptor-gamma agonist properties may be true and clinically relevant antidepressants, even in patients without metabolic comorbidities, improving depression with mechanisms largely unrelated to its insulinsensitizing action $[72,74]$.

Dicholine succinate is a sensitizer of the neuronal insulin receptor and was shown to stimulate insulin-dependent $\mathrm{H} 2 \mathrm{O} 2$ production of the mitochondrial respiratory chain leading to an enhancement of insulin receptor autophosphorylation in neurons. It has an antidepressant-like effect, which might be mediated via the up-regulation of hippocampal expression of insulin growth factor 2, and implicate the neuronal insulin receptor in the pathogenesis of stress-induced depressive syndrome [69].

In a double-blind, placebo-controlled study of 1.496 obese or overweight participants with dyslipidemia and/or hypertension naltrexone plus bupropion or placebo were combined to treat obesity for up to 56 weeks [75]. A significantly greater weight loss was observed with naltrexone/bupropion versus placebo at week 28 and week 56. The treatment moreover produced greater improvements in various cardiometabolic risk markers, participantreported weight-related quality of life, and control of eating [75].

In conclusion, selective serotonin reuptake inhibitors are recommended if possible to treat a depression among patients with diabetes and antidiabetic medications have been shown to induce remission of depression.

\section{Treat inflammation in depression}

Repetitive stressfull experiences lead to a crosstalk between inflammatory pathways and neurocircuits in the brain and result in behavioral responses, such as avoidance and alarm, which are likely to have provided early humans with an evolutionary advantage in their interactions with pathogens and predators [76]. Stressfull interactions in modern times are causal factors for depression, however they are nowadays usually not connected with bodily harm. However, circuits between inflammation and brain appear to drive the development of depression and may contribute to non-responsiveness to current antidepressant therapies [76]. Acutely, inflammatory cytokine administration or activation of the innate immune system produces adaptive behavioral responses that promote conservation of energy to combat infection or recovery from injury. In prolonged stress conditions and depression, proinflammatory cytokines activate the hypothalamic-pituitary-adrenal axis, increase cortisol synthesis, damage neuronal networks and activate peripheral macrophages and central microglia, leading to a dysfunctional endocrine and immune system. Thereby oxidative stress and the neurotoxic N-methyl-D-aspartate glutamate agonist quinolinic acid are increased and contribute to neurodegeneration, which characterises depression particularly in late life [76].

In depression proinflammatory activation of monocytes and macrophages and increased serum levels of proinflammatory cytokines have been confirmed. Furthermore, inflammatory cytokines may serve as mediators of both environmental (e.g. childhood trauma, obesity, stress, and poor sleep) and genetic (functional gene polymorphisms) factors that contribute to depression's development. Additionally, potential therapeutic strategies that target inflammatory cytokine signaling or the consequences of cytokines on neurotransmitter systems in the brain to prevent or reverse cytokine effects on behavior are discussed. As also seen in other stress-induced conditions, i.e. myocardial infarction, coronary heart disease and stroke; pro-inflammatory cytokines, such as tumor necrosis factor alpha, interleukin- 1 and interleukin- 6 stimulate central serotonin neurotransmission 
and are over-expressed in depression, which has been again linked with hypothalamicpituitary-adrenal axis hyperactivity [44] (see Fig. 1).

Interestingly, a special dietary pattern was related to plasma levels of inflammatory markers (C-reactive protein, interleukin-6, tumor necrosis factor $\alpha$ receptor 2) and in a prospective analysis of the relationship of this pattern and depression risk among 43.685 women without depression at baseline relative risks for the strict definition and for the broader definition of depression were both significanty increased (see Fig. 1). Therefore, the inflammatory dietary pattern is associated with a higher depression risk and seems to be influenced by nutritional habits. This finding suggests that chronic inflammation may underlie the association between diet and depression [77] (see Fig. 1).

In overall, depressed patients with chronic heart failure show significantly elevated immune parameters, i.e. interleukin- $2,-4,-6$, interferon- $\gamma$, monocyte chemoattractant protein 1, macrophage inflammatory protein 1 beta and tumor necrosis factor alpha which predict greater severity of depressive symptoms [78].

Tumour necrosis factor alpha is increased in depression and clinical-trial evidence indicates that blocking peripheral tumour necrosis factor alpha has some antidepressant efficacy. In rodents, a recent study adds significantly to the evidence that both peripheral and brain region-specific increases in tumour necrosis factor alpha lead to both sickness and depression- and anxiety disorder-relevant behavior and do so via different pathways 79]. Abnormalities in Toll-like receptor expression (TLR1-9) in depression have been observed in peripheral blood mononuclear cells and postmortem brains of depressed and suicidal patients [80]. The expression of TLR3, TLR4, TLR5, TLR7, TLR8 and TLR9 is elevated in depressed patients and antidepressant treatment completely normalizes TLR3, TLR5, TLR7, TLR8 and TLR9 levels, whereas TLR1, TLR2, TLR4, and TLR6 are decreased to below normal levels ${ }^{75}$. Stress and depression were reported to increase leukocyte and neutrophil counts and to decrease lymphocyte count [81]. Increased production of the main proinflammatory cytokines, such as interleukin-1, interleukin-6, and tumor necrosis factoralpha and of acute phase reactants may play a role in the etiopathogenesis of depression ${ }^{81}$. In major depressed unmedicated patients, significant differences were identified in the neutrophil-lymphocyte ratio, neutrophil count, lymphocyte percentage, and leukocyte values of the patient group when compared with the control group [81]. The counterparts of macrophages in the central nervous system are microglia, which detect and subsequently clear microbial pathogens and injured tissue [82]. They defend again pathogenic organisms and clear and repair damaged tissue [82]. Their defence again pathogenic organisms can be active by alcohol, viruses, vaccination, bacterial membrane components and long-chain saturated fatty acids, which again can lead to depressive symptomatology [82].

However, higher levels of interleukin-6 and CRP predict depressive symptoms at a 5-year follow-up, i.e. a positive association was found between baseline levels of interleukin- 6 and CRP and persistence of depressive symptoms over 5 years [83].

A recent metaanalysis included 6262 patients with depression treated with antiinflammatory substances and showed a beneficial overall effect on depressive symptoms [84] (see Fig. 2).

Longterm interferon-alpha therapy can cause wide-ranging psychiatric side-effects from fatigue, insomnia, anxiety to full-blown depression [85]. Nonsteroidal anti-inflammatory drugs were associated with a better antidepressant effect in general, with 9 of 10 trials favoring NSAIDs, whereas a statistical trend was observed favoring cytokine inhibitors among 4 studies, but the results remained heterogeneous [84]. All randomized studies emphasized the adjunctive antidepressant effects of celecoxib within the first 6 to 8 weeks of antidepressant treatment, which was most pronounced among patients with increased proinflammatory markers [84]. In this context, it is possible, that specific subgroups would benefit more from anti-inflammatory intervention, such as patients with low-grade inflammation or comorbid inflammatory diseases [84]. Anti-inflammatory treatment, in particular celecoxib, decreases depressive symptoms without increasing the risk of adverse 
effects [84]. Identification of subgroups that could benefit from such treatment might be warranted [84].

Moreover, few studies have investigated the potential antidepressant effects of cytokine inhibitors, suggesting an improvement of depression and specific depressive symptoms, such as anxiety and fatigue among patients with psoriasis or ankylosing spondylitis.

The tetracycline antibiotic minocycline may have antidepressant treatment effects [86]. Recent reviews emphasized aspirin because of a more favorable benefit to risk ratio and potentially better antidepressant effects compared with those of selective COX-2 inhibitors [87]. Also aspirin has been associated with additional antidepressant treatment effects, even at low doses [88]. In a meta-analysis of all double-blind, randomized, placebo controlled clinical trials conducted in subjects with depression statins as an adjuvant therapy to antidepressant treatment (i.e. lovastatin, atorvastatin, and simvastatin. largely improved depressive symptoms as assessed by the HDRS [89]. Adjunctive treatment with L-methylfolate calcium significantly improves tumour necrosis factor alpha, interleukin-8, interleukin-6, CRP and leptin levels and treatment outcomes in patients with major depressive disorder [58]. In eight RCTs adjunctive nonsteroidal anti-inflammatory drugs, omega-3 polyunsaturated fatty acids, $\mathrm{N}$-acetylcysteine and pioglitazone have been tested in the treatment of bipolar disorder and show a moderate and statistically significant antidepressant effect [90]. For a number of agents with immunmodulatory properties, i.e. nonsteroidal antiinflammatory drugs, cytokine inhibitors, ketamine, polyunsaturated fatty acids, statins and curcumin clinical trials showed successful treatment of depression [91]. In a 25\% random sample of the Danish population effectiveness and safety measures were compared between periods of SSRI use only and periods of combined SSRI and NSAID or paracetamol use by applying Cox regression [92]. Concomitant NSAID use increased the risk of any psychiatric contact and with depression whereas low-dose acetylsalicylic acid and ibuprofen reduced the risk of psychiatric contact in general and with depression [92].

Synthetic cortisol compounds have shown acute antidepressant effects but because of cortisol's various effects, these results cannot exclusively be ascribed to an anti-inflammatory effect $[93,94]$. Modulation of the mineralocorticoid receptor [95] also improved the effects of antidepressants in randomized, placebo-controlled trials.

The anti-inflammatory action of antidepressants mainly results from their direct interaction with immune cells and from changes in the concentration and the relations of neurotransmitters sensed by these cells [96]. Macrophages are one of the leading cell populations involved in drug-mediated immune effects of antidepressants, which can alleviate chronic inflammation in subjects with depression and in individuals not suffering from depression [90]. Moreover, antidepressants act anti-microbial and anti-tumor immunity [96].

Indeed, antidepressant treatments (monoamine reuptake inhibitors, PDE4 inhibitors, lithium, valproate, agomelatine, tianeptine) inhibit the microglia and macrophage activation [97]. However, the effects of serotonin reuptake inhibitors on inflammatory response, i.e. fluoxetine treatment at least in the hippocampus and in isolated microglia are dependent of environmental conditions, i.e. enriched conditions seem to increase the expression of pro-inflammatory markers while treatment in a stressful conditions seem to produce antiinflammatory effects [98].

In this context, a longitudinal association between any antidepressant use, especially tricyclic agents and subsequent CRP was confirmed several cohort studies [99]. In an openlabel randomized clinical trial the hypothesis was tested that CRP, a commonly available marker of systemic inflammation, predicts differential response to escitalopram and nortriptyline [100]. Indeed, CRP level at baseline differentially predicted treatment outcome with the two antidepressants which was more favorable with escitalopram, when CRP was low and more favorable with nortriptyline when CRP was rather high [100]. Additionally, an association has been described between a clinical antidepressant response and a decrease in markers of systemic inflammation observed during pharmacotherapy with mirtazapine in 
a severely depressed but physically well patient [101]. Also agomelatine reduces CRP levels with associated reduction of depressive symptomatology [102].

Moreover, antidepressant agents bupropion and celecoxib might represent an attractive anti-inflammatory therapeutic strategy for depression [103]. In a randomized, double-blind, placebo-controlled trial sertraline significantly decreased serum level of interleukin-6 [104]. The anti-inflammatory effect of sertraline was independent to its efficacy for depression treatment [104]. Imipramine down-regulates microglial activation, attenuates stress-induced corticosterone and interleukin- 6 responses in plasma, decreases the percentage of monocytes and granulocytes in the bone marrow and circulation and abrogates the accumulation of macrophages in the brain [105]. In an inflammation model of depression in mice, escitalopram, but not R-citalopram and reboxetine, increased pro-inflammatory cytokine and tumour necrosis factor alpha and decreased interleukin-10 [106]. This is interesting in the clinical context of a less efficient antidepressant effect of reboxetine and R-citalopram in a recent metaanalysis [107 , which might be due to their absent antiinflammatory properties.

Lithium acts as an anti-inflammatory agent, which can be connected to abnormal activity of GSK-3 beta and microglia activation via constitutive induction of kinin-B1 receptor and reduction of kinin-B2 receptor expression and activity [108].

Heterocyclic antidepressants, i.e. amitriptyline, clomipramine and maprotiline have an important anti-inflammatory role, which is dependent on the modulation of neutrophil migration and mast cell stabilization [109]. A shift in the balance of the inflammation toward an anti-inflammatory state in the hypothalamus i.e. the expression of members of interleukin-18 system may represent a common mechanism of action of both the chronic treatments with fluoxetine and imipramine [110]. The in vitro literature on antidepressants shows that some antidepressants, such as clomipramine and fluoxetine, more consistently decrease pro-inflammatory cytokines (interleukin-6, interferon-gamma, tumour necrosis factor alpha, whilst others (mirtazapine and venlafaxine) tend to increase their levels [111] In a metaanalysis data from 35 studies treatment nonresponders had higher baseline inflammation parameters and persistently elevated tumour necrosis factor alpha whereas levels of interleukin- 6 decreased during antidepressant treatment [112].

Ketamine, a NMDA antagonist, exerts immediate antidepressant effects at subanaesthetic doses and possesses analgesic and anti-inflammatory activities. Ketamine reduces licking times in neurogenic and inflammatory phases of paw oedema; oedema volumes were reduced by up to $50 \%$ in mice, respectively. While lithium caused no significant effect, ketamine also decreased tumour necrosis factor alpha, iNOS, COX-2 and GSK3 immunostainings in oedematous paws [113]. Fluoxetine and citalopram decrease the release of the amino acids glutamate and d-serine from activated microglia [114]. Venlafaxine and eicosapentanoic acid act anti-inflammatory as venlafaxine decreases interleukin-6, interleukin-8 and interferon gamma inducible protein and eicosapentanoic acid decreases the levels of interleukin-6, interleukin-15, interleukin-1RA and interferon gamma inducible protein. These effects were associated with a corresponding decrease in nuclear factor $\kappa B$ activity [115]. Unexpectedly, sertraline and docosahexaenoic acid had pro-inflammatory effects, with sertraline increasing interferon alpha and interleukin- 6 and docosahexaenoic acid increasing interleukin-15, interleukin-1RA, interferon alpha, and interleukin-6, though these changes were also associated with a decrease in nuclear factor $\mathrm{kB}$ activity, suggesting distinct modes of action. Agomelatine and moclobemide had no effect on interleukin-6 secretion [109].

Also lithium exerts effects on pro- and anti-inflammatory mediators [116], i.e. lithium exerts anti-inflammatory effects (e.g., suppression of cyclooxygenase- 2 expression, inhibition ofinterleukin-1 betaand tumornecrosisfactor- $\alpha$ production, and enhancementofinterleukin-2 and interleukin-10 synthesis). Nevertheless, there is a large body of data which indicates that under certain experimental conditions lithium also exhibits pro-inflammatory properties (e.g., induction of interleukin-4, interleukin-6 and other pro-inflammatory cytokines synthesis) 116]. 


\section{In the treatment of dementia and depression think about lithium}

In a recent meta-analytic evaluation diagnosis of depression was shown to be a risk factor of Alzheimers Dementia [117]. A recent review draws attention to the paucity of research and evidence in the area of antidepressant treatment in patients with dementia accompanied by depressive symptoms [118]. In this cochrane based review only four studies were included, where the effectivity of antidepressant therapy was tested and two of these investigated the properties of drugs not commonly used in this population. Only two studies used selective serotonin reuptake inhibitors and produced two significant differences in favour of treatment, however the tolerability of antidepressant treatment was weak $[119,120]$. In a recent review investigating refractory depression in the elderly, the only treatment for which there was replicated evidence was lithium augmentation [121]. Moreover, lithium might be associated with a reduction in dementia risk and in the risk of cancer [122, 123] (see Fig. 2). Interestingly, a recent metaanalysis suggests that lithium treatment may have beneficial effects on cognitive performance in subjects with mild cognitive impairment and Alzheimers Disease [124].

In terms of comorbidity of depression and dementia anticholinergic antidepressants should not be used as delirium and cognitive deterioration might be increased. Positive effects of SSRI have been shown for behavioural distrubances in dementia 125]. A sufficient treatment of depression in patients with comorbid dementia can have a positive influence on life quality and cognotive functions [126, 127]. In terms of antidepressant use, a positive effect on cognition has to be questioned, i.e. treatment with sertraline in patients with Alzheimers Disease is not associated with greater improvement in cognition at week 24 than treatment with placebo [128]. Cognitive status does not appear to be impacted by short-term pharmacotherapy, at least in patients treated with SSRI and SNRI [129]. Given this potential risk and the myriad of other wellknown adverse effects (i.e. constipation, blurred vision, urinary retention, and delirium) associated with anticholinergic medications, it is prudent to minimize use of these medications and consider alternatives when possible as shown in a recent review [130], However, in this review paroxetine as a highly anticholinergic selective serotonin reuptake inhibitor antidepressant did not increase the risk for dementia when compared with other SSRIs [130]. In the clinical context benzodiazepine use has been associated with an increased risk of dementia, however a recent case control study in 26,459 patients aged $\geq 65$ years with newly diagnosed Alzheimer's disease, long-term use of benzodiazepines was not associated with an increased risk of developing Alzheimer's disease [131 . In conclusion concerning the use of antidepressants in the treatment of dementia an acceptability analysis showed that SSRIs were generally well tolerated but results also suggest that there is insufficient evidence to reject the null hypothesis of no differences in efficacy between SSRIs and placebo in the treatment of depression in dementia [132].

\section{Conclusion}

Depression has been confirmed as a heterogeneous disorder with a subgroup of patients suffering from low-grade chronic inflammation, metabolic disturbances and cardiovascular risk profiles which are frequently resistant to traditional antidepressant treatment. A „depressive" lifestyle might be connected with bad nutritional habits, low exercise, stress, no sleep and a traumatizing environment. This again might lead to low grade inflammation, increased stress hormones to downregulate inflammation and increased risk of diabetes and cardiovascular disease. Fig. 1 shows the pathophysiologic cascade of depression revisited with an exorbitant potential for prohylactic measures, i.e. diet, coping style and exercise, as established also in diabetes and cardiovascular research. In this context, however, at the moment, it is unclear whether individual differences in levels of corresponding biomarkers 
could help match patients to drug treatments that are most likely to be beneficial. In Fig. 2 an attempt is made to include actual findings in a hypothetical but pragmatic clinical intervention strategy.

In future, studies and treatment guidelines are needed to compare the outcome of patients regarding combined interdisciplinar treatment strategies in the context of their comorbidity and to identify those depressed patients who could benefit from drugs acting through inflammatory, cardiosvascular and metabolic pathways.

\section{Disclosure Statement}

Nothing to delare.

\section{References}

1 Gill D, Hatcher S: Antidepressants for depression in medical illness. Cochrane Database Syst Rev 2000;CD001312.

2 Lang UE, Borgwardt S: Molecular mechanisms of depression: perspectives on new treatment strategies. Cell Physiol Biochem 2013;31:761-777.

3 Mathews MJ, Mathews EH, Liebenberg L: The mechanisms by which antidepressants may reduce coronary heart disease risk. BMC Cardiovasc Disord 2015;15:82.

- 4 Sun Y, Vedsted P, Fenger-Grøn M, Wu CS, Bech BH, Olsen J, Benros ME, Vestergaard M: Cancer Mortality in People Treated with Antidepressants before Cancer Diagnosis: A Population Based Cohort Study. PLoS One 2015;10:e0138134.

-5 Ackermann TF, Kempe DS, Lang F, Lang UE: Hyperactivity and enhanced curiosity of mice expressing PKB/ SGK-resistant glycogen synthase kinase-3 (GSK-3).Cell Physiol Biochem 2010;25:775-786.

6 Leibrock C, Ackermann TF, Hierlmeier M, Lang F, Borgwardt S, Lang UE: Akt2 deficiency is associated with anxiety and depressive behavior in mice. Cell Physiol Biochem 2013;32:766-777.

7 Lang UE, Heger J, Willbring M, Domula M, Matschke K, Tugtekin SM: Immunosuppression using the mammalian target of rapamycin (mTOR) inhibitor everolimus: pilot study shows significant cognitive and affective improvement. Transplant Proc 2009;41:4285-4288.

8 Engeli L, Delahaye M, Borgwardt S, Gallinat J, Müller D, Walter M, Lang UE, Beck J: Akt2 Gene is Associated with Anxiety and Neuroticism in Humans. J Vasc Med Surg 2014;2:141.

-9 Martinsson L, Westman J, Hällgren J, Ösby U, Backlund L: Lithium treatment and cancer incidence in bipolar disorder. Bipolar Disord 2016;18:33-40.

10 Stopper H, Garcia SB, Waaga-Gasser AM, Kannen V: Antidepressant fluoxetine and its potential against colon tumors. World J Gastrointest Oncol 2014;6:11-21.

11 Lee HC, Chiu WC, Wang TN, Liao YT, Chien IC, Lee Y, McIntyre RS, Chen PC, Chen VC: Antidepressants and colorectal cancer: A population-based nested case-control study. J Affect Disord 2017;207:353-358.

-12 Pottegård A, Ennis ZN, Hallas J, Jensen BL, Madsen K, Friis S: Long-term use of lithium and risk of colorectal adenocarcinoma: a nationwide case-control study. Br J Cancer. 2016;114:571-575.

13 Wang J, Byers LA: Teaching an Old Dog New Tricks: Drug Repositioning in Small Cell Lung Cancer. Cancer Discov. 2013;3:1333-1335.

14 van Noort V, Schölch S, Iskar M, Zeller G, Ostertag K, Schweitzer C, Werner K, Weitz J, Koch M, Bork P: Novel drug candidates for the treatment of metastatic colorectal cancer through global inverse gene-expression profiling. Cancer Res 2014;74:5690-5699.

15 Bongiorno-Borbone L, Giacobbe A, Compagnone M, Eramo A, De Maria R, Peschiaroli A, Melino G: Antitumoral effect of desmethylclomipramine in lung cancer stem cells. Oncotarget 2015;6:16926-16938.

16 Uzawa K, Kasamatsu A, Shimizu T, Saito Y, Baba T, Sakuma K, Fushimi K, Sakamoto Y, Ogawara K, Shiiba M, Tanzawa H: Suppression of metastasis by mirtazapine via restoration of the Lin-7C/ $\beta$-catenin pathway in human cancer cells. Sci Rep 2014;4:5433. 


\section{SIGíNAis}

Neurosignals 2017;25:54-73

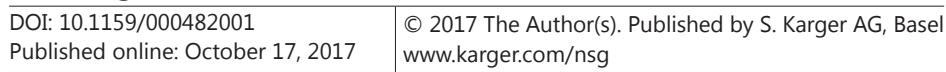

Lang/Walter: Depression and Comorbidity

17 Jahchan NS, Dudley JT, Mazur PK, Flores N, Yang D, Palmerton A, Zmoos AF, Vaka D, Tran KQT, Zhou M, Krasinska K, Riess JW, Neal JW, Khatri P, Park KS, Butte AJ, Sage J: A drug repositioning approach identifies tricyclic antidepressants as inhibitors of small cell lung cancer and other neuroendocrine tumors. Cancer Discov 2013;3:1364-1377.

$\checkmark 18$ Walker AJ, Card T, Bates TE, Muir K: Tricyclic antidepressants and the incidence of certain cancers: a study using the GPRD. British journal of cancer. 2011;104:193-197.

19 McEvoy J, Flores-Otero J, Zhang J, Nemeth K, Brennan R, Bradley C, Krafcik F, Rodriguez-Galindo C, Wilson M, Xiong S, Lozano G, Sage J, Fu L, Louhibi L, Trimarchi J, Pani A, Smeyne R, Johnson D, Dyer MA: Coexpression of normally incompatible developmental pathways in retinoblastoma genesis. Cancer Cell 2011;20:260-275.

-20 Pottegård A, García Rodríguez LA, Rasmussen L, Damkier P, Friis S, Gaist D: Use of tricyclic antidepressants and risk of glioma: a nationwide case-control study. Br J Cancer. 2016;114:1265-1268.

21 Dror N, Mandel M, Lavie G: Unique anti-glioblastoma activities of hypericin are at the crossroad of biochemical and epigenetic events and culminate in tumor cell differentiation. PLoS One 2013;8:e73625.

22 Liu KH, Yang ST, Lin YK, Lin JW, Lee YH, Wang JY, Hu CJ, Lin EY, Chen SM, Then CK, Shen SC: Fluoxetine, an antidepressant, suppresses glioblastoma by evoking AMPAR-mediated calcium-dependent apoptosis. Oncotarget 2015;6:5088-5101.

23 Nevels RM, Gontkovsky ST, Williams BE: Paroxetine-The Antidepressant from Hell? Probably Not, But Caution Required. Psychopharmacol Bull 2016;46:77-104.

-24 Chen VC, Liao YT, Yeh DC, Tseng HC, Stewart R, Lee CT: Relationship between antidepressant prescription and breast cancer: a population based study in Taiwan. Psychooncology 2016;25:803-807.

25 Haque R, Shi J, Schottinger JE, Ahmed SA, Cheetham TC, Chung J, Avila C, Kleinman K, Habel LA, Fletcher SW, Kwan ML: Tamoxifen and Antidepressant Drug Interaction in a Cohort of 16,887 Breast Cancer Survivors. J Natl Cancer Inst 2015;108:337.

-26 Chung ML, Dekker RL, Lennie TA, Moser DK: Antidepressants do not improve event-free survival in patients with heart failure when depressive symptoms remain. Heart Lung 2013;42:85-91.

27 Mun AR, Lee SJ, Kim GB, Kang HS, Kim JS, Kim SJ: Fluoxetine-induced apoptosis in hepatocellular carcinoma cells. Anticancer Res 2013;33:3691-3697.

28 Lowry SJ, Chubak J, Press OW, McKnight B, Weiss NS: Risk of non-Hodgkin lymphoma in relation to tricyclic antidepressant use. Ann Epidemiol 2013;23:349-354.

29 Zhang Z, Du X, Zhao C, Cao B, Zhao Y, Mao X: The antidepressant amitriptyline shows potent therapeutic activity against multiple myeloma. Anticancer Drugs 2013;24:792-798.

-30 Yuan SY, Cheng CL, Ho HC, Wang SS, Chiu KY, Su CK, Ou YC, Lin CC: Nortriptyline induces mitochondria and death receptor-mediated apoptosis in bladder cancer cells and inhibits bladder tumor growth in vivo. Eur J Pharmacol 2015;761:309-320.

- 31 Musselman DL, Somerset WI, Guo Y, Manatunga AK, Porter M, Penna S, Lewison B, Goodkin R, Lawson K, Lawson D, Evans DL, Nemeroff CB: A double-blind, multicenter, parallel-group study of paroxetine, desipramine, or placebo in breast cancer patients (stages I, II, III, and IV) with major depression. J Clin Psychiatry 2006;67:288-296.

-32 Cankurtaran ES, Ozalp E, Soygur H, Akbiyik DI, Turhan L, Alkis N: Mirtazapine improves sleep and lowers anxiety and depression in cancer patients: superiority over imipramine. Support Care Cancer 2008;16:1291-1298.

-33 Nemeroff CB, Goldschmidt-Clermont PJ: Heartache and heartbreak--the link between depression and cardiovascular disease. Nat Rev Cardiol 2012;9:526-539.

-34 Stewart JC, Perkins AJ, Callahan CM: Effect of collaborative care for depression on risk of cardiovascular events: data from the IMPACT randomized controlled trial. Psychosom Med 2014;76:29-37.

-35 Cooper DC, Trivedi RB, Nelson KM, Reiber GE, Eugenio EC, Beaver KA, Fan VS: Antidepressant adherence and risk of coronary artery disease hospitalizations in older and younger adults with depression. J Am Geriatr Soc 2014;62:1238-1245. 


\section{SiquNAis}

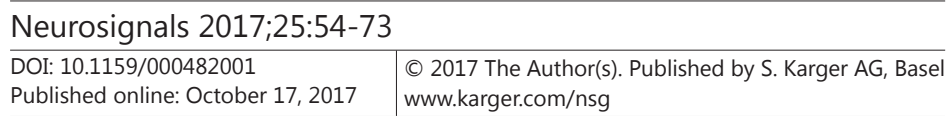

Lang/Walter: Depression and Comorbidity

-36 Blumenthal JA, Sherwood A, Babyak MA, Watkins LL, Smith PJ, Hoffman BM, O'Hayer CV, Mabe S, Johnson J, Doraiswamy PM, Jiang W, Schocken DD, Hinderliter AL: Exercise and pharmacological treatment of depressive symptoms in patients with coronary heart disease: results from the UPBEAT (Understanding the Prognostic Benefits of Exercise and Antidepressant Therapy) study. J Am Coll Cardiol 2012;60:10531063.

-37 Thombs BD, Roseman M, Coyne JC, de Jonge P, Delisle VC, Arthurs E, Levis B, Ziegelstein RC: Does evidence support the American Heart Association's recommendation to screen patients for depression in cardiovascular care? An updated systematic review. PLoS One 2013;8:e52654.

-38 Chung CM, Kuo TM, Chiang SL, Wang ZH, Hung CC, Lane HY, Liu CS, Ko YC: Antidepressants in association with reducing risk of oral cancer occurrence: a nationwide population-based cohort and nested casecontrol studies. Oncotarget 2016;7:11687-11695.

-39 Zuidersma M, Conradi HJ, van Melle JP, Ormel J, de Jonge P: Depression treatment after myocardial infarction and long-term risk of subsequent cardiovascular events and mortality: a randomized controlled trial. J Psychosom Res 2013;74:25-30.

-40 Abbasi SH, Mohammadinejad P, Shahmansouri N, Salehiomran A, Beglar AA, Zeinoddini A, Forghani S, Akhondzadeh S: Simvastatin versus atorvastatin for improving mild to moderate depression in postcoronary artery bypass graft patients: A double-blind, placebo-controlled, randomized trial. J Affect Disord 2015;183:149-155.

41 Williams LJ, Pasco JA, Mohebbi M, Jacka FN, Stuart AL, Venugopal K, O'Neil A, Berk M: Statin and Aspirin Use and the Risk of Mood Disorders among Men. Int J Neuropsychopharmacol doi:10.1093/ijnp/pyw008.

42 Coupland C, Hill T, Morriss R, Moore M, Arthur A, Hippisley-Cox J: Antidepressant use and risk of cardiovascular outcomes in people aged 20 to 64 : cohort study using primary care database. BMJ 2016;352:i1350

43 Empana JP, Prugger C, Thomas F, Perier MC, Zanoli L, Castiglioni P, Guibout C, Causeret S, Barnes C, Lemogne C, Parati G, Laurent S, Pannier B, Boutouyrie P, Jouven X: Serotonin and norepinephrine reuptake inhibitors antidepressant use is related to lower baroreflex sensitivity independently of the severity of depressive symptoms. A community-study of 9213 participants from the Paris Prospective Study III. Atherosclerosis 2016;251:55-62.

-44 Muto T, Usuda H, Yamamura A, Yoshida K, Ohashi A, Mitsui-Saitoh K, Sakai J, Sugimoto Y, Mizutani H, Nonogaki T, Hotta Y: Protective effects of fluvoxamine against ischemia/reperfusion injury in isolated, perfused guinea-pig hearts. Biol Pharm Bull 2014;37:731-739.

45 Guner I, Yaman MO, Aksu U, Uzun D, Erman H, Inceli M, Gelisgen R, Yelmen N, Uzun H, Sahin G: The effect of fluoxetine on ischemia-reperfusion after aortic surgery in a rat model. J Surg Res 2014;189:96-105.

46 Bernardo BC, Blaxall BC: From Bench to Bedside: New Approaches to Therapeutic Discovery for Heart Failure. Heart Lung Circ 2016;25:425-434.

47 Ribback S, Pavlovic D, Herbst D, Nedeljkov-Jancic R, Wendt M, Nedeljkov V, Bleich S, Frieling H: Effects of amitriptyline, fluoxetine, tranylcypromine and venlafaxine on rat vascular smooth muscle in vitro--the role of the endothelium. J Physiol Pharmacol 2012;63:119-125.

48 Scuteri A, Modestino A, Fedullo F, Assisi AP, Gianni W: Depression treatment selectively modifies arterial stiffness in older participants. J Gerontol A Biol Sci Med Sci 2013;68:719-725.

-49 Bismuth-Evenzal Y, Gonopolsky Y, Gurwitz D, Iancu I, Weizman A, Rehavi M: Decreased serotonin content and reduced agonist-induced aggregation in platelets of patients chronically medicated with SSRI drugs. J Affect Disord 2012;136:99-103.

-50 Staudacher I, Wang L, Wan X, Obers S, Wenzel W, Tristram F, Koschny R, Staudacher K, Kisselbach J, Koelsch P, Schweizer PA, Katus HA, Ficker E, Thomas D: hERG K+ channel-associated cardiac effects of the antidepressant drug desipramine. Naunyn Schmiedebergs Arch Pharmacol 2011;383:119-139.

-51 Blankfield RP, Iftikhar IH: Food and drug administration regulation of drugs that raise blood pressure. J Cardiovasc Pharmacol Ther 2015;20:5-8.

-52 Bismut H, Caron M, Coudray-Lucas C, Capeau J: Glucose contribution to nucleic acid base synthesis in proliferating hepatoma cells: a glycine-biosynthesis-mediated pathway. Biochem J 1995;308:761-767.

-53 O’Neil A, Sanna L, Redlich C, Sanderson K, Jacka F, Williams LJ, Pasco JA, Berk M: The impact of statins on psychological wellbeing: a systematic review and meta-analysis. BMC Med 2012;10:154. 


\section{SiqíNAis}

Neurosignals 2017;25:54-73

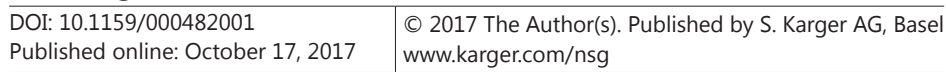

Lang/Walter: Depression and Comorbidity

-54 Jørgensen TS, Wium-Andersen IK, Wium-Andersen MK, Jørgensen MB, Prescott E, Maartensson S, KraghAndersen P, Osler M: Incidence of Depression After Stroke, and Associated Risk Factors and Mortality Outcomes, in a Large Cohort of Danish Patients. JAMA Psychiatry 2016;73:1032-1040.

55 Li CT, Bai YM, Tu PC, Lee YC, Huang YL, Chen TJ, Chang WH, Su TP: Major depressive disorder and stroke risks: a 9-year follow-up population-based, matched cohort study. PLoS One 2012;7:e46818.

56 Wang MT, Chu CL, Yeh CB, Chang LC, Malone DC, Liou JT: Antidepressant use and risk of recurrent stroke: a population-based nested case-control study. JAMA Psychiatry 2014;71:1381-1391.

-57 Jennum P, Baandrup L, Iversen HK, Ibsen R, Kjellberg J: Mortality and use of psychotropic medication in patients with stroke: a population-wide, register-based study. BMJ Open 2016;6:e010662.

-58 Angermann CE, Gelbrich G, Störk S, Gunold H, Edelmann F, Wachter R, Schunkert H, Graf T, Kindermann I, Haass M, Blankenberg S, Pankuweit S, Prettin C, Gottwik M, Böhm M, Faller H, Deckert J, Ertl G: MOODHF Study Investigators and Committee Members. Effect of Escitalopram on All-Cause Mortality and Hospitalization in Patients With Heart Failure and Depression: The MOOD-HF Randomized Clinical Trial. Ann Pharmacother 2016;50:253-261.

-59 Brodrick JE, Mathys ML: Antidepressant Exposure and Risk of Dementia in Older Adults with Major Depressive Disorder. J Am Geriatr Soc 2016;64:2517-2521.

60 Hendrickx H, McEwen BS, Ouderaa F: Metabolism, mood and cognition in aging: the importance of lifestyle and dietary intervention. Neurobiol Aging 2005;26:1-5.

61 Shelton RC, Miller AH: Eating ourselves to death (and despair): the contribution of adiposity and inflammation to depression. Prog Neurobiol 2010;91:275-299.

62 Shelton RC, Pencina MJ, Barrentine LW, Ruiz JA, Fava M, Zajecka JM, Papakostas GI: Association of obesity and inflammatory marker levels on treatment outcome: results from a double-blind, randomized study of adjunctive L-methylfolate calcium in patients with MDD who are inadequate responders to SSRIs. J Clin Psychiatry 2015;76:1635-1641.

-63 Bouwman V, Adriaanse MC, van 't Riet E, Snoek FJ, Dekker JM, Nijpels G: Depression, anxiety and glucose metabolism in the general dutch population: the new Hoorn study. PLoS One 2010;5:e9971.

-64 McIntyre RS, Soczynska JK, Konarski JZ, Woldeyohannes HO, Law CW, Miranda A, Fulgosi D, Kennedy SH: Should Depressive Syndromes Be Reclassified as "Metabolic Syndrome Type II"? Ann Clin Psychiatry 2007;19:257-266.

65 Wexler DJ, Porneala B, Chang Y, Huang ES, Huffman JC, Grant RW: Diabetes differentially affects depression and self-rated health by age in the US. Diabetes Care 2012;35:1575-1577.

66 Gois C, Akiskal H, Akiskal K, Figueira ML: The relationship between temperament, diabetes and depression. J Affect Disord 2012;142:S67-71.

67 Cline BH, Steinbusch HW, Malin D, Revishchin AV, Pavlova GV, Cespuglio R, Strekalova T: The neuronal insulin sensitizer dicholine succinate reduces stress-induced depressive traits and memory deficit: possible role of insulin-like growth factor 2. BMC Neurosci 2012;13:110.

-68 Shao W, Ahmad R, Khutoryansky N, Aagren M, Bouchard J: Evidence supporting an association between hypoglycemic events and depression. Curr Med Res Opin 2013;29:1609-1615.

-69 Roopan S, Larsen ER: Use of antidepressants in patients with depression and comorbid diabetes mellitus: a systematic review. Acta Neuropsychiatr 2016;25:1-13.

-70 Kleinridders A, Cai W, Cappellucci L, Ghazarian A, Collins WR, Vienberg SG, Pothos EN, Kahn CR: Insulin resistance in brain alters dopamine turnover and causes behavioral disorders. Proc Natl Acad Sci USA 2015;112:3463-3468.

-71 Isaac R, Boura-Halfon S, Gurevitch D, Shainskaya A, Levkovitz Y, Zick Y: Selective serotonin reuptake inhibitors (SSRIs) inhibit insulin secretion and action in pancreatic cells. J Biol Chem 2013;288:5682-5693.

72 Wheatcroft SB: Teaching an old drug new tricks: can paroxetine ease the burden of cardiovascular disease in diabetes? Diabetes 2013;62:698-700.

73 Colle R, de Larminat D, Rotenberg S, Hozer F, Hardy P, Verstuyft C, Fève B, Corruble E: Pioglitazone could induce remission in major depression: a meta-analysis. Neuropsychiatr Dis Treat 2016;13:9-16.

74 Kashani L, Omidvar T, Farazmand B, Modabbernia A, Ramzanzadeh F, Tehraninejad ES, Ashrafi M, Tabrizi M, Akhondzadeh S: Does pioglitazone improve depression through insulin-sensitization? Results of a randomized double-blind metformin-controlled trial in patients with polycystic ovarian syndrome and comorbid depression. Psychoneuroendocrinology 2013;38:767-776. 
Lang/Walter: Depression and Comorbidity

75 Apovian CM, Aronne L, Rubino D, Still C, Wyatt H, Burns C, Kim D, Dunayevich E; COR-II Study Group: A randomized, phase 3 trial of naltrexone SR/bupropion SR on weight and obesity-related risk factors (CORII). Obesity (Silver Spring) 2013;21:935-943.

76 Miller AH, Raison CL: The role of inflammation in depression: from evolutionary imperative to modern treatment target. Nat Rev Immunol 2016;16:22-34.

77 Lucas M, Chocano-Bedoya P, Schulze MB, Mirzaei F, O'Reilly ÉJ, Okereke OI, Hu FB, Willett WC, Ascherio A: Inflammatory dietary pattern and risk of depression among women. Brain Behav Immun 2014;36:46-53.

78 Xiong GL, Prybol K, Boyle SH, Hall R, Streilein RD, Steffens DC, Krishnan R, Rogers JG, O'Connor CM, Jiang W; SADHART-CHF Investigators: Inflammation Markers and Major Depressive Disorder in Patients With Chronic Heart Failure: Results From the Sertraline Against Depression and Heart Disease in Chronic Heart Failure Study. Psychosom Med 2015;77:808-815.

79 Klaus F, Paterna JC, Marzorati E, Sigrist H, Götze L, Schwendener S, Bergamini G, Jehli E, Azzinnari D, Fuertig R, Fontana A, Seifritz E, Pryce CR: Differential effects of peripheral and brain tumor necrosis factor on inflammation, sickness, emotional behavior and memory in mice. Brain Behav Immun 2016;58:310326.

80 Hung YY, Huang KW, Kang HY, Huang GY, Huang TL: Antidepressants normalize elevated Toll-like receptor profile in major depressive disorder. Psychopharmacology (Berl) 2016;233:1707-1714.

-81 Demir S, Atli A, Bulut M, İbiloğlu AO, Güneş M, Kaya MC, Demirpençe Ö, Sır A: Neutrophil-lymphocyte ratio in patients with major depressive disorder undergoing no pharmacological therapy. Neuropsychiatr Dis Treat 2015;11:2253-2258.

-82 Kalkman HO, Feuerbach D: Antidepressant therapies inhibit inflammation and microglial M1-polarization. Pharmacol Ther 2016;163:82-93.

-83 Zalli A, Jovanova O, Hoogendijk WJ, Tiemeier H, Carvalho LA: Low-grade inflammation predicts persistence of depressive symptoms. Psychopharmacology 2016;233:1669-1678.

-84 Kohler O, Benros ME, Nordentoft M, Farkouh ME, Iyengar RL, Mors O, Krogh J: Effect of Anti-inflammatory Treatment on Depression, Depressive Symptoms, and Adverse Effects A Systematic Review and Metaanalysis of Randomized Clinical Trials. JAMA Psychiatry 2014;71:1381-1391.

85 Kovacs D, Kovacs P, Eszlari N, Gonda X, Juhasz G: Psychological side effects of immune therapies: symptoms and pathomechanism. Curr Opin Pharmacol 2016;29:97-103.

86 Miyaoka T, Wake R, Furuya M, Liaury K, Ieda M, Kawakami K, Tsuchie K, Taki M, Ishihara K, Araki T, Horiguchi J: Minocycline as adjunctive therapy for patients with unipolar psychotic depression: an openlabel study. Prog Neuropsychopharmacol Biol Psychiatry 2012;37:222-226.

87 Fond G, Hamdani N, Kapczinski F, Boukouaci W, Drancourt N, Dargel A, Oliveira J, Le Guen E, Marlinge E, Tamouza R, Leboyer M: Effectiveness and tolerance of anti-inflammatory drugs' add-on therapy in major mental disorders: a systematic qualitative review. Acta Psychiatr Scand 2014;129:163-179.

-88 Mendlewicz J, Kriwin P, Oswald P, Souery D, Alboni S, Brunello N: Shortened onset of action of antidepressants in major depression using acetylsalicylic acid augmentation: a pilot open-label study. Int Clin Psychopharmacol 2006;21:227-231.

-89 Salagre E, Fernandes BS, Dodd S, Brownstein DJ, Berk M: Statins for the treatment of depression: A metaanalysis of randomized, double-blind, placebo-controlled trials. J Affect Disord 2016;200:235-242.

-90 Rosenblat JD, Kakar R, Berk M, Kessing LV, Vinberg M, Baune BT, Mansur RB, Brietzke E, Goldstein BI, McIntyre RS: Anti-inflammatory agents in the treatment of bipolar depression: a systematic review and meta-analysis. Bipolar Disord 2016;18:89-101.

-91 Schmidt FM, Kirkby KC, Lichtblau N: Inflammation and Immune Regulation as Potential Drug Targets in Antidepressant Treatment. Curr Neuropharmacol 2016;14:674-687.

-92 Köhler O, Petersen L, Mors O, Gasse C: Inflammation and depression: combined use of selective serotonin reuptake inhibitors and NSAIDs or paracetamol and psychiatric outcomes. Brain Behav 2015;5:e00338.

-93 Arana GW, Santos AB, Laraia MT, McLeod-Bryant S, Beale MD, Rames LJ, Roberts JM, Dias JK, Molloy M: Dexamethasone for the treatment of depression: a randomized, placebo-controlled, double-blind trial. Am J Psychiatry 1995;152:265-267.

$\$ 94$ DeBattista C, Posener JA, Kalehzan BM, Schatzberg AF: Acute antidepressant effects of intravenous hydrocortisone and CRH in depressed patients: a double-blind, placebo-controlled study. Am J Psychiatry 2000;157:1334-1337. 
Lang/Walter: Depression and Comorbidity

95 Otte C, Hinkelmann K, Moritz S, Yassouridis A, Jahn H, Wiedemann K, Kellner M: Modulation of the mineralocorticoid receptor as add-on treatment in depression: a randomized, double-blind, placebocontrolled proof-of-concept study. J Psychiatr Res 2010;44:339-346.

96 Nazimek K, Strobel S, Bryniarski P, Kozlowski M, Filipczak-Bryniarska I, Bryniarski K: The role of macrophages in anti-inflammatory activity of antidepressant drugs. Immunobiology 2016;S01712985:30320-30325.

-97 Kalkman HO, Feuerbach D: Antidepressant therapies inhibit inflammation and microglial M1-polarization. Pharmacol Ther 2016;163:82-93.

-98 Alboni S, Benatti C, Montanari C, Tascedda F, Brunello N: Chronic antidepressant treatments resulted in altered expression of genes involved in inflammation in the rat hypothalamus. Eur J Pharmacol 2013;721:158-167.

99 Hamer M, Batty GD, Marmot MG, Singh-Manoux A, Kivimäki M: Anti-depressant medication use and C-reactive protein: results from two population-based studies. Brain Behav Immun 2011;25:168-173.

100 Uher R, Tansey KE, Dew T, Maier W, Mors O, Hauser J, Dernovsek MZ, Henigsberg N, Souery D, Farmer A, McGuffin P: An inflammatory biomarker as a differential predictor of outcome of depression treatment with escitalopram and nortriptyline. Am J Psychiatry 2014;171:1278-1286.

101 Alikhan SM, Lee JA, Dratcu L: Mirtazapine treatment of a severe depressive episode and resolution of elevated inflammatory markers. Case Rep Psychiatry 2013;2013:697872.

102 De Berardis D, Fornaro M, Orsolini L, Iasevoli F, Tomasetti C, de Bartolomeis A, Serroni N, De Lauretis I, Girinelli G, Mazza M, Valchera A, Carano A, Vellante F, Matarazzo I, Perna G, Martinotti G, Di Giannantonio M: Effect of agomelatine treatment on C-reactive protein levels in patients with major depressive disorder: an exploratory study in "real-world," everyday clinical practice. CNS Spectr 2016;5:1-6.

103 Maciel IS, Silva RB, Morrone FB, Calixto JB, Campos MM: Synergistic effects of celecoxib and bupropion in a model of chronic inflammation-related depression in mice. PLoS One 2013;8:e77227.

104 Taraz M, Khatami MR, Dashti-Khavidaki S, Akhonzadeh S, Noorbala AA, Ghaeli P, Taraz S: Sertraline decreases serum level of interleukin-6 (IL-6) in hemodialysis patients with depression: results of a randomized double-blind, placebo-controlled clinical trial. Int Immunopharmacol 2013;17:917-923.

105 Ramirez K, Sheridan JF: Antidepressant imipramine diminishes stress-induced inflammation in the periphery and central nervous system and related anxiety- and depressive- like behaviors. Brain Behav Immun 2016;57:293-303.

106 Dong C, Zhang JC, Yao W, Ren Q Yang C, Ma M, Han M, Saito R, Hashimoto K: Effects of escitalopram, R-citalopram, and reboxetine on serum levels of tumor necrosis factor- $\alpha$, interleukin-10, and depressionlike behavior in mice after lipopolysaccharide administration. Pharmacol Biochem Behav 2016;144:7-12.

107 Cipriani A, Furukawa TA, Salanti G, Geddes JR, Higgins JP, Churchill R, Watanabe N, Nakagawa A, Omori IM, McGuire H, Tansella M, Barbui C: Comparative efficacy and acceptability of 12 new-generation antidepressants: a multiple-treatments meta-analysis. Lancet 2009;373:746-758.

108 Naaldijk YM, Bittencourt MC, Sack U, Ulrich H: Kinins and microglial responses in bipolar disorder: a neuroinflammation hypothesis. Biol Chem 2016;397:283-296.

109 Gurgel JA, Lima-Júnior RC, Rabelo CO, Pessoa BB, Brito GA, Ribeiro RA: Amitriptyline, clomipramine, and maprotiline attenuate the inflammatory response by inhibiting neutrophil migration and mast cell degranulation. Rev Bras Psiquiatr 2013;35:387-392.

110 Alboni S, Poggini S, Garofalo S, Milior G, El Hajj H, Lecours C, Girard I, Gagnon S, Boisjoly-Villeneuve S, Brunello N, Wolfer DP, Limatola C, Tremblay MÈ, Maggi L, Branchi I: Fluoxetine treatment affects the inflammatory response and microglial function according to the quality of the living environment. Brain Behav Immun 2016;58:261-271.

111 Baumeister D, Ciufolini S, Mondelli V: Effects of psychotropic drugs on inflammation: consequence or mediator of therapeutic effects in psychiatric treatment? Psychopharmacology 2016;233:1575-1589.

112 Strawbridge R, Arnone D, Danese A, Papadopoulos A, Herane Vives A, Cleare AJ: Inflammation and clinical response to treatment in depression: A meta-analysis. Eur Neuropsychopharmacol 2015;25:1532-1543.

113 do Vale EM, Xavier CC, Nogueira BG, Campos BC, de Aquino PE, da Costa RO, Leal LK, de Vasconcelos SM, Neves KR, de Barros Viana GS: Antinociceptive and Anti-Inflammatory Effects of Ketamine and the Relationship to Its Antidepressant Action and GSK3 Inhibition. Basic Clin Pharmacol Toxicol 2016;119:562573. 
114 Dhami KS, Churchward MA, Baker GB, Todd KG: Fluoxetine and citalopram decrease microglial release of glutamate and D-serine to promote cortical neuronal viability following ischemic insult. Mol Cell Neurosci 2013;56:365-374.

115 Horowitz MA, Wertz J, Zhu D, Cattaneo A, Musaelyan K, Nikkheslat N, Thuret S, Pariante CM, Zunszain PA: Antidepressant compounds can be both pro- and anti-inflammatory in human hippocampal cells. Int J Neuropsychopharmacol 2014;18.

116 Nassar A, Azab AN: Effects of lithium on inflammation. ACS Chem Neurosci 2014;5:451-458.

$\checkmark 117$ Ownby RL, Crocco E, Acevedo A, John V, Loewenstein D: Depression and risk for Alzheimer disease: systematic review, meta-analysis, and metaregression analysis. Archives of General Psychiatry 2006;63:530-538.

118 Bains J, Birks JS, Dening TR: The efficacy of antidepressants in the treatment of depression in dementia. Cochrane Database Syst Rev 2002: CD003944.

119 Petracca G, Tesón A, Chemerinski E, Leiguarda R, Starkstein SE: A double-blind placebo-controlled study of clomipramine in depressed patients with Alzheimer's disease. J Neuropsychiatry Clin Neurosci 1996;8:270-275.

120 Lyketsos CG, Lopez O, Jones B, Fitzpatrick AL, Breitner J, DeKosky S: Prevalence of neuropsychiatric symptoms in dementia and mild cognitive impairment: results from the cardiovascular health study. JAMA 2002;288:1475-1483.

-121 Cooper C, Katona C, Lyketsos K, Blazer D, Brodaty H, Rabins P, de Mendonça Lima CA, Livingston G: A systematic review of treatments for refractory depression in older people. Am J Psychiatry 2011;168:681688.

122 Berk M, Cowdery S, Williams L, Malhi GS: Recalibrating the risks and benefits of lithium therapy. Br J Psychiatry 2017;211:1-2.

123 Kessing LV, Gerds TA, Knudsen NN, Jørgensen LF, Kristiansen SM, Voutchkova D, Ernstsen V, Schullehner J, Hansen B, Andersen PK, Ersbøll AK: Association of Lithium in Drinking Water With the Incidence of Dementia. JAMA Psychiatry doi: 10.1001/jamapsychiatry.2017.2362.

124 Matsunaga S, Kishi T, Annas P, Basun H. Hampel H, Iwata N: Lithium as a Treatment for Alzheimer's Disease: A Systematic Review and Meta-Analysis. J Alzheimers Dis 2015;48:403-410.

125 Henry GD, Williamson RR. Tampi: Efficacy and tolerability of antidepressants in the treatment of behavioral and psychological symptoms of dementia, a literature review of evidence. Am J Alzheimers Dis Other Demen 2011;26:169-183.

126 Gallassi R, Di Sarro R, Morreale A, Amore M: Memory impairment in patients with late-onset major depression: the effect of antidepressant therapy. J Affect Disord 2006;91:243-250.

127 Teri L, Logsdon RG, Uomoto J, McCurry SM: Behavioral treatment of depression in dementia patients: a controlled clinical trial. J Gerontol B Psychol Sci Soc Sci 1997;52:159-166.

128 Munro CA, Brandt J, Sheppard JM, Steele CD, Samus QM, Steinberg M, Rabins PV, Lyketsos CG: Cognitive outcomes after sertaline treatment in patients with depression of Alzheimer disease. Am J Geriatr Psychiatry 2012;20:1036-1044.

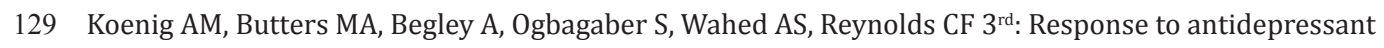
medications in late-life depression across the spectrum of cognitive functioning. J Clin Psychiatry $2014 ; 75: 2$.

130 Gray SL, Hanlon JT: Anticholinergic medication use and dementia: latest evidence and clinical implications. Ther Adv Drug Saf 2016;7:217-224.

131 Imfeld P, Bodmer M, Jick SS, Meier CR: Benzodiazepine Use and Risk of Developing Alzheimer's Disease or Vascular Dementia: A Case-Control Analysis. Drug Safe 2015;38:909-919.

132 Skapinakis P, Bakola E, Salanti G, Lewis G, Kyritsis AP, Mavreas V: Efficacy and acceptability of selective serotonin reuptake inhibitors for the treatment of depression in Parkinson's disease: a systematic review and meta-analysis of randomized controlled trials. BMC Neurol 2010;10:1471-2377. 